This item was submitted to Loughborough's Institutional Repository (https://dspace.lboro.ac.uk/) by the author and is made available under the following Creative Commons Licence conditions.

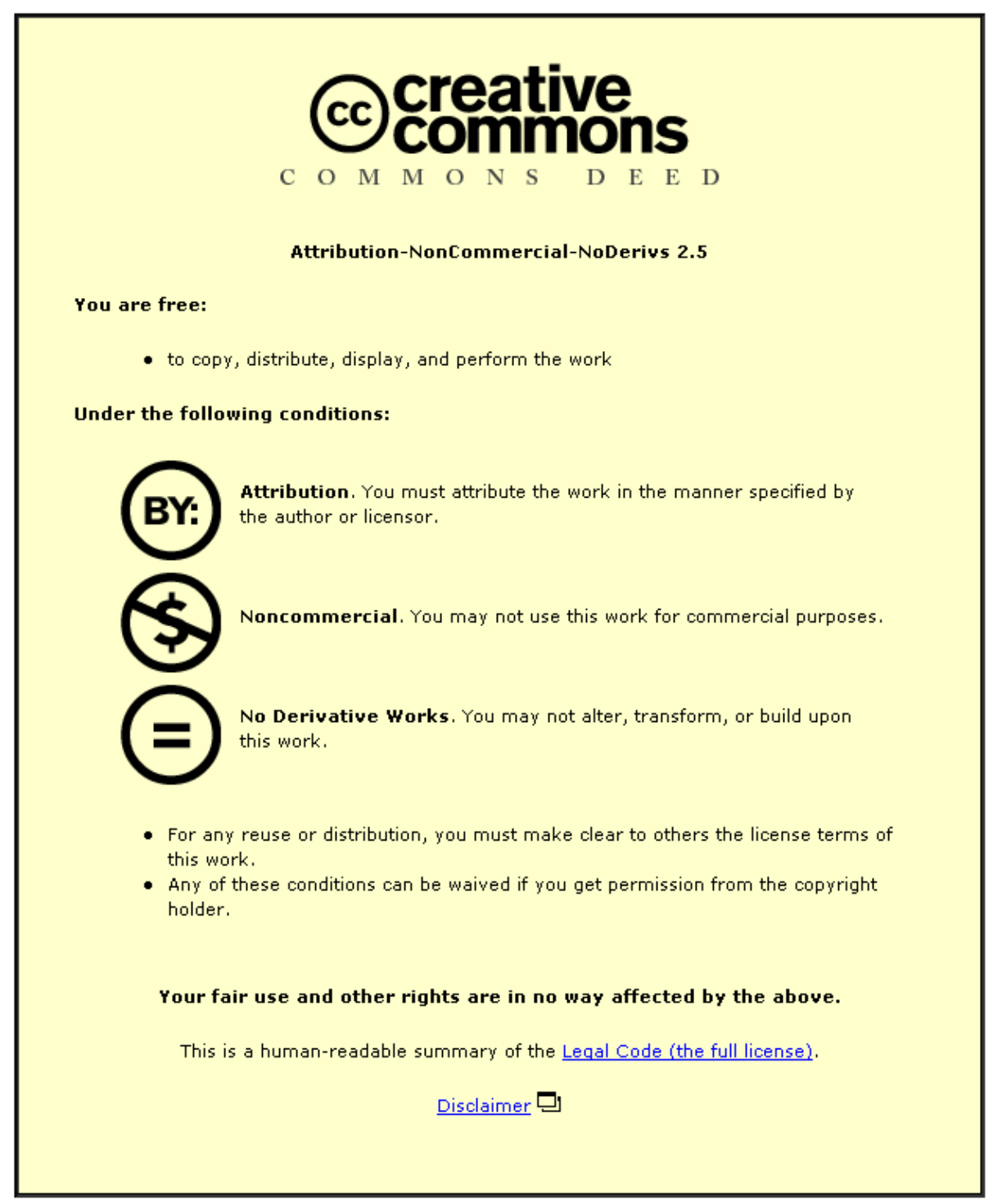

For the full text of this licence, please go to: http://creativecommons.org/licenses/by-nc-nd/2.5/ 


\title{
A DESIGN ERGONOMICS APPROACH TO ACCESSIBILITY AND USER NEEDS IN TRANSPORT.
}

\author{
R. Marshall ${ }^{1}$, D.E. Gyi ${ }^{3}$, K. Case ${ }^{2}$, J.M. Porter ${ }^{1}$, R.E. Sims ${ }^{1}$ S.J. Summerskill ${ }^{1}$, \\ and P. Davis ${ }^{1}$,
}

\author{
1. Department of Design and Technology, 2. Department of Mechanical and \\ Manufacturing Engineering, 3. Department of Human Sciences, Loughborough \\ University, Loughborough, UK
}

\begin{abstract}
This paper describes research carried out into the area of accessibility and 'design for all'. The Accessibility and User Needs in Transport (AUNT-SUE) project was initiated to develop and test sustainable policies and practice that would deliver effective socially inclusive design and operation in transport and the public realm. Loughborough University's role in the project focuses on the provision of data on users that is accessible, valid, and applicable and a means of utilising the data to assess the accessibility of designs during the early stages of development. These needs have led to the development of our inclusive design tool called HADRIAN.

Data were collected on 100 people the majority of whom are older or have some form of impairment. These data include size, shape, capability, preferences and experiences with a range of daily activities and transport related tasks. These are partnered with a simple task analysis system. The system supports the construction of a task linked to a CAD model of a design to be evaluated. The task is then carried out by the virtual individuals in the database. Accessibility issues are reported by the system allowing excluded people to be investigated. Thus HADRIAN supports designers and ergonomists in attempting to 'design for all' by fostering empathy with the intended users, meeting their data needs through an accessible and applicable database and providing a means of gaining some of the feedback possible with a real user trial at a much earlier stage in the design process.
\end{abstract}

\section{Introduction}

Research has identified that there is a clear and well established need for all those involved in the design of products, services and environments to take an inclusive approach, and avoid discriminating or disadvantaging users based on their size, shape, age, abilities, needs, or aspirations (Coleman et al, 2003). This need is driven by a number of factors: the ageing population (WHO, 2008), increasing legislation (DDA, 2005), and a strong moral case that design should not be embodying a philosophy that prevents certain people from using, and enjoying the outcomes that it produces. The persuasiveness of these drivers together with the perceived support for inclusive design amongst the design community would suggest that evidence of inclusively designed outcomes would be common place. However this is often not the case with many designs still primarily catering for the younger and able-bodied. 
We believe that there is, therefore, a need for a new approach in order to effectively support designers when attempting to 'design for all' that must take into account a number of important issues:

- Tools are often data driven. If the data is unavailable, inaccurate, misleading, unapplicable or just difficult to apply then often the tool is of limited value.

- Even with accurate, applicable data, tools provide an additional layer of activity and often require some expertise. If a design team lacks the expertise in a particular discipline tools may be used to mitigate against this. Assuming tools are easy to use it can often be the case that the tool is used without a full understanding of the results or advice provided by the tool.

- Tools are rarely good at addressing the softer, cognitive or emotional issues within design. Even if the tool manages this element of design well, it is not straightforward what needs to be done.

This paper describes our current research as part of the AUNT-SUE project to provide better support for designers in their efforts to design for all. AUNT-SUE (Accessibility and User Needs in Transport for Sustainable Urban Environments, Porter et al, 2006) is a consortium of UK academic institutions including London Metropolitan University, University College London and Loughborough University, together with local councils and other public and private bodies such as Camden Council, Hertfordshire Council, and the RNIB. The consortium's aim is to produce methodologies for sustainable policies and practices that will deliver effective socially inclusive design and operation of transport and is funded as part of the EPSRC's SUE programme.

\section{Our approach to inclusive design}

Our current approach to inclusive design was driven by an early survey of 50 designers which aimed to identify the current situation in designing when taking into account the needs of older and disabled people (Gyi et al, 2000). The results highlighted that available data tends to be 'patchy' and rarely in sufficient detail to enable design professionals to make more informed decisions. In addition, existing data tools are not in a format or language that designers can access and relate to easily. Finally it was noted that the majority of designers used at least one computer aided design package. These findings have also been identified amongst a broader range of concerns for businesses in a more recent study by Goodman et al (2006). From this we identified that there is a clear need to provide ergonomics data in a highly visual form and to integrate design for all philosophy into existing good practice, such as the use of CAD and other computer based design tools such as SAMMIE (System for Aiding Man Machine Interaction Evaluation, Porter et al, 2004).

Human modelling systems such as SAMMIE allow ergonomics issues to be explored in a CAD environment during concept design. The benefits of being able to explore issues such as fit, posture, reach and vision at an early stage of the design are invaluable in achieving products that fully accommodate users. 
There are many issues when trying to apply ergonomics data to design and the same is true of ergonomics tools such as human modelling systems. Sources of anthropometric data often have limitations on how representative they are for any given design exercise. Concerns with the age of the data, access to data on appropriate Nationalities, the support for designing from 5th-95th \%iles, the lack of task specificity, and so on. These concerns are compounded when the vast majority of the existing data do not relate to older or disabled people. In addition, the successful use of such tools is often coloured or constrained by the need for 'expert' users. For ergonomists to truly support widespread design practice, we need to develop and communicate information and methods that meet the needs of designers themselves.

In response to these issues it was decided to develop an inclusive design tool. This tool is called HADRIAN (Human Anthropometric Data Requirements Investigation and Analysis, Marshall et $a l, 2004)$ and works together with SAMMIE to target the first two bullet points outlined in the introduction, namely: the provision of relevant, accessible and holistic information on people of a broad range of size, shape, and ability and a means of utilizing the available information to assess the inclusiveness of a proposed design. Together the tools support 'playing' with ideas at an early stage in the design process and provide feedback as to the impact of those ideas on users. In principle, the tools take the model of fitting trials, or user trials that are performed with real people and real products and move that into a virtual world where the costs and complexities of the real world are avoided and yet 'some' of the valuable feedback is available in a much more timely manner.

\section{Design relevant data on people}

HADRIAN comprises a database of physical and behavioural data on 102 people covering a broad range of ages and abilities. The age of people in the database ranges from 18 to 89 years with 46 people who are over 60 . Within the sample 59 people have some form of impairment including: limb loss, asthma, blood conditions, cerebral palsy, epilepsy, head injuries, non specific knee problems, multiple sclerosis, arthritis, vision and hearing impairments, heart problems, paraplegia, Parkinson's disease, stroke, and dyslexia, amongst others. Of the 43 able bodied people 20 were aged over 60 and had undiagnosed or minor impairments associated with being older. In addition, the sample also contains people who reported difficulties with using some forms of transport impaired by issues such as pushchair use.

The sample is clearly not representative of the more general population. To address the lack of data in this area and to directly support designers in inclusive design it was a deliberate decision to skew the data towards those who are older and/or with some form of impairment. Whilst the sample is biased it has been carefully selected to cover as broad a range as possible for every measure recorded.

The data consist of 26 Anthropometric body measures and 18 joint angle ranges of motion (see Table 1 for a summary of all the available data). For those people who use a wheelchair four wheelchair measures were also taken. A somatotype value is used to record body shape (Carter and Heath, 1990) in addition to two digital photographs taken from the front and side of the subject. Reach range is recorded in the form of an envelope of coordinate data centred upon the shoulder. These coordinates describe a surface mesh representing the boundary of reach capability for the subject's arm (Figure 1). 


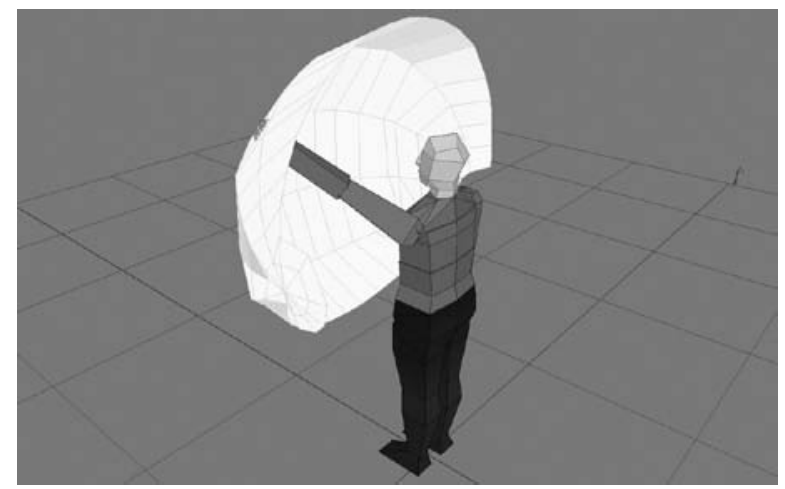

Figure 1. Reach envelopes define the boundary of reach capability for an individual.

In addition to traditional anthropometric measures the data also contain a whole body scan. Using a [TC]2 whole body scanning system, subjects have been scanned to capture their body form. Body scan data is not available for all of the people in the database due to a number of limitations with the system. In particular, wheelchair users could not be scanned in their own wheelchair as the chair would interfere with the scanning process.

In order to address issues with the applicability of existing data sources it was decided that the database should contain functional data in addition to anthropometry. Based upon a survey of user needs, conducted with 50 older and disabled people (Oliver et al, 2001) three areas were identified for investigation: a range of generic kitchen based tasks, a range of seating scenarios, and ingress and egress from a range of public transport types. Taking a pragmatic approach the data collection focused on tasks that were sufficiently specific to be relevant to design needs, yet generically applicable so that we were not designing a kitchen design tool, or creating a system that required data on every possible task situation in order to be useful. Using a kitchen rig consisting of wall and floor units together with a mock up of an oven, participants were asked to pick and place a range of one handed and two handed loads to various locations. A second rig was used to simulate entering and exiting from UK rail, coach and bus vehicles with a representative range of step heights and handle locations. Where possible the data collected reflects real-world application. Thus, comfort maximums were recorded to reflect what the subject would be likely to attempt in reality where absolute maximums would not normally be used.

All task activity was recorded from two positions via digital video camera and subsequently used to provide video clips of tasks being performed. Task data stored within the database includes a success or a failure for each task element. In addition, the data also records how a task was performed in terms of coded task behaviour.

AUNT-SUE has also seen an expansion of the database beyond the physical into cognitive, emotional and sensory data associated with travel. Whilst these are often complex they are also the source of some of the most fundamental issues in transport accessibility. Using a questionnaire on transport activities, data were captured for each individual's ability to deal with tasks such as using trains, buses, trams, London-style taxi cabs and minicab taxis; as well as issues surrounding travelling with luggage; the types and frequency of journeys made; problems using stairs, lifts or escalators; route planning, dealing with crowds, understanding signs and other public information, and perceptions of crime and personal safety. Thus the questionnaire provides information concerning issues that may arise at any point during the whole journey process. 
Table 1. Summary of data in HADRIAN database.

\begin{tabular}{|c|c|c|}
\hline 1. Anthropometry (mm) & 2. Joint constraints (deg) & Ingress / egress: step up / step \\
\hline Stature & Shoulder extension/flexion & down from maximum comfortable \\
\hline Weight & Shoulder abduction/adduction & step height, two handle types, \\
\hline Arm length & Upper arm extension/flexion & maximum of 4 handle locations \\
\hline Upper arm length & Upper arm abduction/adduction & \\
\hline Elbow-to-shoulder (link) & Upper arm medial/lateral rotation & 7. Additional capability \\
\hline Wrist-to-elbow (link) & Elbow extension/flexion & Bending to touch toes \\
\hline Abdominal depth (standing) & Elbow pronation/supination & Getting up from lying down \\
\hline Abdominal depth (sitting) & Wrist extension/flexion & Reaching to tie shoelaces \\
\hline $\begin{array}{l}\text { Thigh depth (standing) } \\
\text { Thigh depth (sitting) }\end{array}$ & Wrist abduction/adduction & $\begin{array}{l}\text { Twisting upper body to left and } \\
\text { right }\end{array}$ \\
\hline Knee-to-hip (link) & 3. Reach range ( $\sim 100$ & Peg test (dexterity) \\
\hline Ankle-to-knee (link) & coordinates mm) & Grip strength \\
\hline Ankle height & Functional reach volume & Vision \\
\hline Foot length & generated by dominant arm/hand & \\
\hline Sitting height & & 8. Transport questionnaire \\
\hline $\begin{array}{l}\text { Sitting shoulder height } \\
\text { Hip-to-shoulder (link) }\end{array}$ & 4. Somatotype (3 digit number) & $\begin{array}{l}\text { (question and answer transcripts } \\
\text { and videos) }\end{array}$ \\
\hline Chest height & 5. Whole body scan (VRML file) & Transport use (frequency etc) \\
\hline Chest depth & & Issues with transport usage \\
\hline Head height & 6. Task capability (encoded & (problems, assistance required etc) \\
\hline Eye-to-top-of-head & postures for each task plus task & Issues with lifts, steps, escalators \\
\hline Buttock-knee length & videos) & Issues with environment (personal \\
\hline Knee height & 4 pick \& place tasks (high shelf, & safety etc) \\
\hline Shoulder breadth & worksurface, oven, low shelf) & Issues with signage and timetables \\
\hline Hip breadth & with 3 load types (cup, bag, tray) & Local issues \\
\hline Hand length & each set to maximum & \\
\hline Hand grip length & $\begin{array}{l}\text { comfortable weight, } 1 \text { or } 2 \text { hands } \\
\text { as appropriate. }\end{array}$ & $\begin{array}{l}\text { 8. Background } \\
\text { Age }\end{array}$ \\
\hline Wheelchair length & & Nationality \\
\hline Wheelchair height & Seating: 2 designs - high \& hard, & Occupation / work history \\
\hline Wheelchair width & low \& soft; restricted access to & Handedness \\
\hline Wheelchair seat height & single side (bus), both sides & Disability \\
\hline & (toilet cubicle), no restriction. & Front and side photographs \\
\hline
\end{tabular}

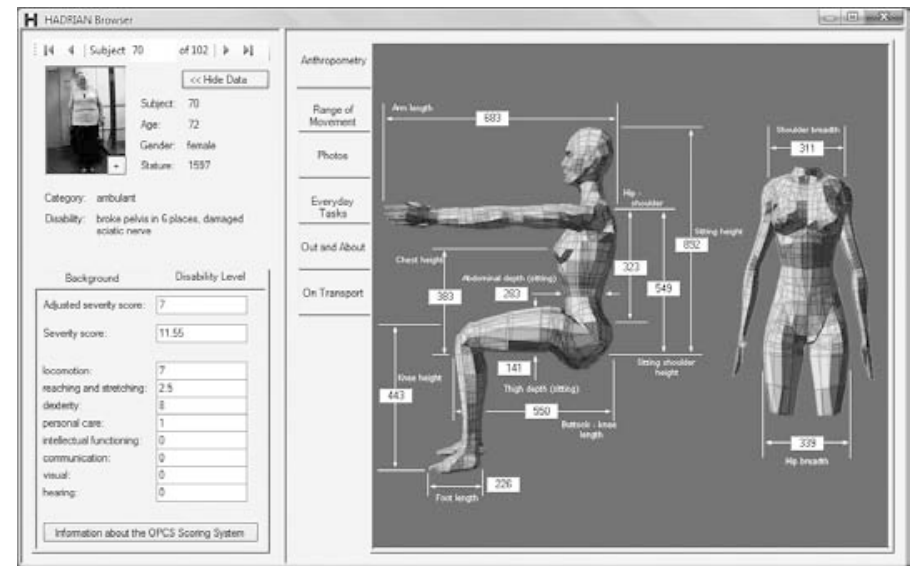

Figure 2. Data in the database is structured around individual people.

A key feature of the database is how the data are presented (Figure 2). To address concerns with designers being presented with faceless numbers, with the lack of visualization in current tools, and in the complexities of multivariate accommodation, the database is effectively a catalogue of individuals. Data are not broken down into categories of individual measures but are instead 
maintained as a set associated with a single person. Thus the user can browse through the people in the database see a picture of that individual and explore the data about that person. This approach fosters empathy between the designer and the people who they are designing for, and attempts to minimize the dehumanizing effects of percentiles and of the virtual environment in which the design is being created.

\section{A means of applying the data to design problems}

To address the utilization of the data to assess the inclusiveness of a proposed design, HADRIAN also includes a simple task analysis system. HADRIAN focuses on an integrated approach to support the designer in defining a task description associated with using their design, subsequent analysis of the task performed with the design, and final result reporting and analysis feedback. This approach then aids the designer in the evaluation of a specific design, establishing a form of semi-automated virtual fitting trial. This fitting trial can then be performed many times using the individuals in the database as virtual subjects.

The analysis system was designed to facilitate a means of describing how a product would be used. 'Product' is taken in its broadest context and may include any object that requires physical interaction. The system allows a complete task such as "purchase ticket from ticket machine" to be broken down into recognizable elements such as "select ticket type" or rather its interpretation as "reach to touch-screen". The dynamic process of performing a task is broken down into static 'frames' associated with these elements. SAMMIE is then used to model the elements of these static frames including a posture for the human model, a target object, and an environment. The system then responds to each individual task element in a chain, performing physical interactions, and assessing the success of each element towards completing the task.

The actual process of describing a task element involves selecting a task command such as Look, Reach, View, Move and so on. The command then needs a target that will be represented within the model to be analysed. This target will be the focus of the task element and form a verb + noun pairing such as Look at Screen, Reach to Card Slot. The task definition is then completed through the specification of task parameters. This may include an acceptable viewing distance, a particular grip type to adopt, or what limb a reach should be performed with.

In an attempt to make the analysis as realistic as possible the system encodes the task behaviour recorded in the database. This behaviour is then replicated when an individual in the database is asked to perform a task of a similar nature. Thus, HADRIAN synthesizes how the task is performed by each individual in the database as the task progresses.

Whilst a full treatment of the analysis model is beyond the scope of this paper, various factors are taken into consideration during this process including the dominant hand of the individual, the current orientation of the individual, the nearest limb to the target, any impairments to the non dominant limb, the details of the next task element, and so on.

Irrespective of the underlying complexity of the process, the designer sees individuals in the database attempting to perform the task as defined. Each individual will have their own size, shape, capability and behaviour represented in the human model. The individuals will all perform the task slightly differently based on the process outlined above. The outcome of the 
analysis is then reported to the designer in terms of a percentage excluded. The percentage is based upon those individuals in the database and so if 5 of the 100 people fail to achieve the task then $5 \%$ are reported excluded. The designer can then explore those who failed, identify exactly what individuals experienced problems, with what part of the task and why. The designer may now explore the affects of changes to the design or even the task. Because the process is occurring during an early stage of the design, possibilities can be rapidly explored and an optimum quickly identified.

\section{Ongoing developments}

HADRIAN's development has been targeted at addressing discrete design problems or products. However, the concept of inclusive transport is not solely related to any single piece of design, rather it concerns a network or system of designed elements. These designs could include everything from a flight of steps to a train carriage and yet they all form potential barriers to travel. This network is part of the transport infrastructure, combining a number of directly related, and indirectly related design problems that must be addressed holistically if inclusive transport is taken in the context of the 'journey'.

To succeed in providing truly accessible transport we must be able to ensure that a door-to-door journey for example, from home to the doctor, or from the bank to the theatre is possible at every stage. Two tools are being developed to address this need; the Inclusive Journey Planner and the Journey Stress Calculator. The inclusive Journey Planner addresses the needs of end users by providing improved information on accessibility along the whole length of a journey. The system then allows much more informed decision making on route and transport mode choice before the journey is undertaken. The Journey Stress Calculator supports the needs of transport professionals by allowing HADRIAN style analyses of a whole journey. This enables transport professional and practitioners to identify which people are most likely to avoid a journey, compare the accessibility of different routes and ensure spending is targeted at removing stressors that cause greatest exclusion (Davis et al 2009).

HADRIAN is also going through a process of validation (Summerskill et al, 2009). Validation will consist of three phases that will compare the findings from: HADRIAN used by a designer, SAMMIE used by an experienced ergonomist, and a real user trial conducted by an experienced ergonomist. All three assessments will use people from the HADRIAN database in real or virtual form to assess a number of existing transport related designs. The results will be used to refine HADRIAN.

\section{Conclusion}

HADRIAN has been developed to support designers and ergonomists in developing inclusive products addressing limitations with current data and tools. The HADRIAN databaseprovides extensive data on 102 individuals including their size, shape, ability, behaviour, and range of other information on their background and specific transport related experiences. This data can then be employed through a simple task analysis system to assess the inclusiveness of a design. This predictive process greatly increases the chance that designers will identify issues that users may experience with a design long before the design is complete. 
HADRIAN is currently undergoing validation to assess its performance and to ensure that it is useable by the people it was designed to support. The database and analysis system will be made available to designers to support their efforts and help establish inclusive design as an integrated part of design practice.

\section{References}

Carter, J.E. and Heath, B.H., 1990. Somatotyping Development and Applications, Cambridge: Cambridge University Press.

Coleman, R., Lebbon, C., Clarkson, J. and Keates S., 2003. From Margins to Mainstream, In: J. Clarkson et al eds, Inclusive Design, design for the whole population, London: Springer-Verlag, pp 1-25.

Davis, P., Marshall, R., Case, K., Porter, J.M., Summerskill, S.J., Gyi, D.E. and Sims, R.E., 2009. Reducing the stress of using public transport. In: Contemporary Ergonomics 2009, proceedings of the Annual Conference of the Ergonomics Society. London, UK, April 2009.

DDA., 2005. Disability Discrimination Act 2005 [online]. Office of Public Sector Information. Available from: http://www.opsi.gov.uk/acts/acts2005/ukpga_20050013_en_1 [Accessed 01/09/2008].

Goodman, J., Dong, H., Langdon, P.M. and Clarkson, P.J., 2006. Industry's response to inclusive design: a survey of current awareness and perceptions. In: P.D. Bust ed. Contemporary Ergonomics 2006, proceedings of the Annual Conference of the Ergonomics Society. Cambridge, UK, April 2006, pp. 368-372.

Gyi, D.E., Porter, J.M. and Case, K., 2000. Design practice and 'designing for all', Proceedings of the IEA 2000/HFES Congress, Human Factors and Ergonomics Society, San Diego, California, USA, August 2000.

Marshall, R., Case, K., Porter, J.M., Sims, R.E. and Gyi, D.E., 2004. Using HADRIAN for Eliciting Virtual User Feedback in 'Design for All', Journal of Engineering Manufacture; Proceedings of the Institution of Mechanical Engineers, Part B, 218(9), 1st September 2004, 1203-1210.

Martin, J., Meltzer, H. and Elliot, D., 1994. OPCS surveys of disability in Great Britain: The prevalence of disability among adults, London: HMSO.

Oliver, R.E., Gyi, D.E., Porter, J.M., Marshall, R. and Case, K., 2001. A Survey of the Design Needs of Older and Disabled People, In: M.A. Hanson ed. Contemporary Ergonomics 2001 proceedings of the Annual Conference of the Ergonomics Society. Cirencester: Taylor \& Francis, 2001, pp 365-370.

Porter, J.M., Case, K., Marshall, R., Gyi, D.E. and Sims, R.E., 2006. Developing the HADRIAN inclusive design tool to provide a personal journey planner, In: P.D. Bust ed. Contemporary Ergonomics 2006, proceedings of the Annual Conference of the Ergonomics Society. Cambridge, UK, April 2006, pp. pp 465-469.

Porter, J.M., Marshall, R., Freer, M. and Case, K., 2004. SAMMIE: a computer aided ergonomics design tool. In: N.J. Delleman, C.M. Haslegrave, and D.B. Chaffin eds. Working Postures and Movements - tools for evaluation and engineering. Boca Raton: CRC Press LLC, 454-462.

Summerskill, S.J., Marshall, R., Gyi, D.E., Porter, J.M., Case, K., Sims, R.E. and Davis, P., 2009. Validation of the HADRIAN System with a Train Station Design Case Study. In: Contemporary Ergonomics 2009, proceedings of the Annual Conference of the Ergonomics Society. London, UK, April 2009.

WHO, 2008. WHO Ageing [online]. World Health Organisation. Available from: http://www.who.int/topics/ageing/en/ [Accessed 01/09/2008]. 